\title{
What Difference Does Psychoanalysis Training Make in Psychiatric Clinical Practice?
}

\author{
Chang Hun Lee \\ Leechanghun Psychiatric Clinic, Ulsan, Korea
}

\author{
정신분석 수련(Psychoanalysis Training)이 정신과 임상에 어떤 영향을 미칠 것인가? \\ 이 창 훈 \\ 이창훈정신건강의학과의원
}

Psychiatrists must learn and experience various fields of psychiatric medicine and sciences in order to be able to comprehensively understand the human mind and pathological mental phenomena. Without this all-encompassing expertise, they will not be able to adequately treat and prevent psychiatric illnesses in terms of neurobiology, psychodynamic psychiatry, and socio-cultural psychiatry. I insist that psychodynamic psychiatry, which is a requirement for psychiatrists to learn and practice during clinical work, must be included as an essential part of resident training for psychiatrists. I wonder however, whether the current training curriculum for psychiatric residents is sufficient for imparting the understanding and experience of psychodynamic psychiatry. Currently, there is an increasing need for training in psychodynamic psychiatry among psychiatric clinicians and psychiatric residents since they recognize that psychodynamic approaches should be applied in order for them to better understand and treat psychiatric illnesses more effectively. By reflecting on the changes in my own identity and clinical practice after being trained in psychoanalysis, I have tried to identify the difference that training in psychoanalysis makes in the clinical practice of psychiatrists and its influence on their personal and professional life. In conclusion, I want to emphasize that training in psychodynamic psychiatry is essential and valuable for clinical psychiatrists as well as for the training of psychiatric residents.

Psychoanalysis 2016;27(1):2-6

KEY WORDS: Psychoanalysis · Training $\cdot$ Psychodynamic psychiatry $\cdot$ Clinical practice.

Received: December 11, 2015 Revised: January 9, 2016 Accepted: January 11, 2016

Address for correspondence: Chang Hun Lee, MD

Leechanghun Psychiatric Clinic, 241 Daegongwon-ro, Nam-gu, Ulsan 44667, Korea

Tel: +82-52-265-2051, Fax: +82-52-265-2071, E-mail: drchanghunlee@gmail.com

\section{서 론}

현대 정신의학은 인간의 건강한 정신적 현상에서부터 병 리적 정신질환까지, 생물학적, 정신역동적, 사회문화적 측면 에서 사람들을 이해하고 치료하고, 사람들이 건강한 정신심 리 상태를 유지하도록 돕기 위해 노력하고 있다. 정신과 의 사들은 전공의 수련기간 동안 이 목적에 부합하는 능력을 갖추기 위한 필수적인 학문뿐만 아니라 다양한 분야의 학문 을 접해야 한다. 저자는 정신과 임상의로서 정신과 의사가 반 드시 숙지하고 임상진료에 적용해야 하는 분야로 역동정신

This is an Open Access article distributed under the terms of the Creative Commons Attribution Non-Commercial License (http://creativecommons.org/licenses/by-nc/3.0) which permits unrestricted non-commercial use, distribution, and reproduction in any medium, provided the original work is properly cited.
의학이 포함된다고 생각한다. 그러나 최근의 정신과 전공의 수련과정이 역동정신의학적 이해와 경험을 제공하는 데 충 분한지에 대해서는 의문을 가지고 있다. 정신과 전공의 수련 과정 중의 역동정신의학의 교육이 불충분한 것이 세계적인 추세인데, Gabbard(2005)는 최근 전공의 수련이 생물학적 치료에 대한 교육과 실습에 중점을 두고 있으나, 많은 전공 의들이 인간의 정신병리를 이해하고 임상적으로 적용하는 데 있어서 현재 정신과 수련 커리큘럼의 한계를 느끼고 있 다고 했다. 점차 심층적인 역동정신의학을 통해 인간의 정신 과 병리를 이해하고 병리적 현상을 치료하는 데 적용하고자 하는 욕구와 필요가 또 다시 늘어나고 있다고 지적했다. $\mathrm{Yu}$ 와 $\mathrm{Ha}(2015)$ 역시 한국의 정신과 전공의 수련과정은 물론이 고 정신과 전문의들에게 정신분석과 정신분석적 정신치료 의 수련이 꼭 필요하고, 실제로 이 과정에 입학하길 원하는 
정신과 전공의와 전문의들이 수년간 큰 폭으로 늘어났다고 했다.

나는 정신분석가가 되겠다는 꿈을 가지고 의과대학에 입 학했다. 내가 의과대학을 다녔던 시기와 그 지역의 의학적 환경은 정신분석이나 정신치료가 환영받지 못하는 분위기 였고, 생물정신의학이 강조되었다. 적잖이 실망한 나는 정신 분석을 접할 수 있는 수련병원을 택하여 정신과 전공의 수 련과정을 밟았다. 나의 정신과 전공의 수련은 역시 생물정신 의학이 중점이 되었지만, 정신치료를 배우고 경험하는 데 지 지적이었고 정신역동의학에 대한 내 열의가 방해받지 않았 다. 그럼에도 불구하고 정신과 전문의로서 임상진료를 하면 서 내가 체감한 것은, 전공의 과정 동안 배우고 경험한 정신 역동의학적 지식과 이해로는 실제 임상에서 환자를 진료하 면서 적용하기가 매우 부족하다는 것이었다. 그리하여 나는 국제정신분석학회 한국 Study Group(한국정신분석학회)에 지원하여 정신분석가 수련과정을 졸업하였고, 이제는 정신 분석가로서 환자들을 진료하고 있다.

나의 정신분석 수련 전후의 변화를 돌아봄으로써, 내가 경 험한 정신분석가 수련이 환자들의 치료와 임상에 어떤 영향 을 미쳤으며, 정신과 임상의로서 직업적, 개인적 삶이 어떤 영향을 받았는지 돌아보고, 정신과 의사의 정신역동 수련의 필요성과 그 가치에 대해 생각해 보는 기회를 독자들과 나누 었으면 한다. 저자의 개인적이고 주관적인 경험을 서술하는 것이며, 개인의 의견이 객관적인 통념을 대표할 수는 없겠지 만, 이를 통해 현대 정신의학에서 역동정신의학자의 역할의 의미와 중요성을 재조명하고 정신의학자들이 이에 대해 활 발한 논의를 할 수 있는 초석이 되기를 바란다.

\section{본 론}

\section{정신분석 수련이란 무엇인가?}

정신분석과 그 수련과정의 의미와 의의를 설명하기 위해 미국정신분석학회의 '정신분석 교육 및 수련 기준(standard for education and training in psychoanalysis)'을 인용하고 자 한다.

정신분석은 사람의 마음을 연구하는 학문이다. 정신분석은 인간의 마음을 완전히 표현하고 탐구하며 이해하기 위한 치료 방법이자 연구 방법 중의 하나이며, 우리 자신에 대한 이해와 정서적 성장과 그 변화가 지속될 가능성을 키워준다.

정신분석 수련의 우선적인 목표는 수련생들의 정신분석적 능력과 정신분석적 정체성의 발달을 촉진하는 것이다. 이 정체
성의 정수는 과학적 질문의 자세와 새로운 것을 향한 호기심, 그리고 축적된 정신분석적 지식을 포괄적으로 이해하고자 하 는 소망이다. 또한 분석가로서 지속적인 연구와 자기 발전을 위해 끊임없이 노력하고, 주기적으로 동료들에게 조언(consult), 지도감독(supervision)을 받으며, 환자를 돌봄에 있어 진 정한 책임을 다하는 것이다(American Psychoanalytic Association 2015).

정신분석 수련은 개인 교육분석이라는 지극히 개인적인 경험으로 시작하여, 정신분석적 치료과정을 효과적으로 수 행하기 위해 필수적인 이론과 임상기술, 윤리적 자세를 교육 한다. 궁극적으로 수련생들이 독립적인 정신분석을 수행할 수 있도록 지도감독을 받는 임상치료에서 지도감독 없이 임 상치료를 할 수 있도록 돕는다. 정신분석 수련과정을 졸업한 다는 것은 수련생이 독립적으로 정신분석 치료를 훌륭히 수 행할 수 있다는 것을 증명하는 것이 된다.

정신분석 수련은 전공의 수련과정보다 훨씬 긴 것이 일반 적이며, 수련과정 동안 후보생들에게 요구되는 헌신은 상당 하다고 할 수 있다. 후보생들은 수련과정을 밟아 나갈수록 자 신의 일상생활과 임상진료의 전반적인 영역이 정신역동적 개념과 이해에 점차 푹 빠지는 경험을 하게 된다. 고도로 전 문화된 직업인들의 훈련과정은 그 분야를 불문하고 훈련생 들에게 지식과 기술을 연마시키는 것만이 아니라, 훈련생들 의 정체성과 성격의 형성에도 어느 정도 영향을 미친다고 생 각하는데, 정신분석 수련은 그야말로 후보생들의 성격과 정 체성의 변화와 통합에 지대한 영향을 미치며, 수련을 통해 자 신과 세상, 그리고 자신의 환자들에 대한 이해와 태도가 상 당히 변화하게 된다고 생각한다.

나 역시 분석수련 동안, 나의 성격과 대상관계를 심층에 이르기까지 이해하게 되고, 또한 점차 변화했다. 자신에 대한 이해와 변화는 자연스럽게 내가 일상에서 만나는 사람들, 특 히 진료 중에 만나는 환자들에 대한 시각에 변화를 일으키 고, 그들에 대한 이해의 폭과 깊이, 그들과 나의 만남-상호작 용을 인식하고 이해하는 태도와 방식에 근본적인 변화를 가 져왔다. 내가 치료하는 정신역동적 정신치료와 정신분석의 내담자에게는 두말할 나위도 없겠지만, 약물치료를 위한 진 료에서도 환자들의 이해와 진료방식과 이에 대한 가치관, 상 호작용을 이해하는 방식에 변화를 일으켰다. 저자는 정신분 석적 정신치료와 정신분석 이외의 일반적인 정신과 임상진 료에 정신분석 수련이 어떠한 영향을 주었는지에 대해서 중 점적으로 살펴봄으로써 정신분석과 정신과 임상진료의 상호 영향을 보다 강조하여 살펴볼 것이다. 


\section{정신과 임상진료에서 역동정신의학이 왜 중요한가?}

Gabbard(2005)는 현대정신의학에서 역동정신의학자의 역 할(dynamic psychiatrist)을 피력하면서, 정신과 전공의들이 환자들의 정신과 질환을 진단만이 아닌, 이해하기 위한 연구 방법을 원하며, 정신과 전문의들도 환자들이 약물에 반응하 지 않을 때 난처함을 호소하고 있다고 했다. 2차세계대전 후 융성했던 정신분석은 1960년대에 이르러 생물정신의학이 획기적으로 성장하면서 서서히 빛을 잃게 되었다(Bahn 2014). 그러나 오늘날 정신과 의사들은 다시금 생물학적 정신의학 의 여러 한계들에 직면했다. 수십 년간 정신분석은 뼈아픈 성 찰을 통해 현시대가 요구하는 학문이자 치료적 방법이 되기 위한 노력을 멈추지 않았다(Gabbard 2005). 역동적 접근의 진정한 소득은 질병발생에서 성격이 어떤 역할을 하는지에 주의를 기울일 수 있는 것이고, 성격의 구조를 이해하지 않고 서는 증상을 치료할 수 없다(Michels 1988).

역동정신치료적 접근이 모든 정신과 질환을 효과적으로 치료할 수는 없지만, 대부분의 환자들에게 있어 역동지향적 인 접근은 치료자가 훨씬 깊고 폭넓게 환자를 이해하고 효 과적으로 치료하도록 도울 것이다. 무엇보다 환자의 치료에서 불가피하지만 큰 영향을 미치는 역전이 문제를 이해하고 해 결하기 위해서는 역동정신의학의 적용이 반드시 필요하다(Gabbard 2005).

\section{정신분석 수련이 나의 정신과 임상진료에 어떤 영향과 변화를 일으켰나?}

나의 정신과 전공의 수련과정에서 역동정신의학에 대한 교육과 수련이 비교적 풍부했다고 할 수 있음에도, 정신과 전 문의가 된 후 실제 임상영역에서는 환자의 치료를 약물요법 에 의존할 수밖에 없는 현실이었다. 한 환자에게 할애되는 짧은 진료시간과 하루에 할당된 많은 수의 환자들, 무엇보다 전적으로 약물치료 중심인 기존 정신과 진료에 익숙해진 환 자들을 치료하는 것은 역동정신의학을 적용하기에는 힘든 환경이었다. 따라서 약물치료가 효과를 내지 못하는 경우, 환 자를 치료할 다른 전략이 있다고 하더라도 환자가 받아들이 기 쉽지 않았고, 치료자 역시 시간과 비용이 몇 배나 더 드는 다른 치료전략을 시도하기가 거의 불가능했다. 자연스럽게 진료시간은 환자가 약을 얼마나 잘 먹는지 약물 순응도를 확 인하고 교육하는 것에 집중이 되었고, 약물치료로 증상이 호 전된 후에도 상당기간 약물유지요법을 써야 하는 만성정신 질환의 경우, 진료는 매우 단조로워질 수밖에 없었다. 또 신 환을 처음 면담할 때 환자의 증상을 평가하고 진단하고, 약 물치료 계획을 세우기 위한 면담기법 외에 면담기술이 부족 하다 보니, 환자와 나 양쪽 모두 긴 면담이 추가적으로 필요
하다고 느끼지 못하곤 했다. 심지어 환자가 약물치료로 증상 이 많이 호전될 경우, 치료자에게 이상적인 기대를 가지고 나 에게 의지하면 상당히 부담스럽게 느껴지고, 나의 역전이 감 정을 극복하기가 힘들었다. 환자를 처음 면담하여 약물치료 로 호전이 되고, 장기간의 약물유지요법을 한다고 하더라도 치료경과에 대한 이해가 부족하여 어떤 요인이 환자를 호전 하도록 했는지, 아니면 왜 치료효과가 없었는지 판단하기가 힘들었다. 이런 진료환경 속에서 나는 전문의 자격을 취득한 지 수개월 만에 점차 정신과 임상의로서 자긍심과 긍정적인 기대가 줄어들고 정체성을 잃어가는 것을 체감했다.

그러나 지금 돌아보면 나의 정신과 의사로서의 정체성과 치료활동을 제한하는 가장 큰 요인은 열악한 진료환경이기 보다는 내 자신 안에 있었다. 이상(ideal)을 임상에 적용하는 데에는 용기와 포기와 관용이 필요하며 그것이 가능하기 위 해 끝없이 노력해야 한다는 것을 깨닫게 되었다. 나에게는 그 것을 깨닫게 도와준 것이 정신분석 훈련과정이었다.

개인 교육분석을 통해 내 자신에 대한 불신과 미래에 대 한 매우 근본적인 두려움을 깨닫게 되었다. 내가 가진 잠재 력과 이미 성취한 자원조차도 이용하지 못하고 있는 내 자신 의 두려움을 바라보고 극복하면서, 점차 사람들과 세계에 대 한 이해의 폭과 깊이도 더해졌다. 특히 환자들에게 진심으로 다가가는 것이 어떤 것인지를 깨달을 수 있었다. 정신역동적 인 이론과 이해가 바탕이 되어야 함은 물론이지만, 모든 지 식과 기술을 습득했다고 하더라도 치료자가 자신이 가진 것 을 환자들과의 관계에서 활용하기 위해서는 치료자의 중립 적 자세에 위배되는 개인적인 갈등과 욕구를 솔직하게 인정 하고 극복하려는 자세 없이는 환자들에게 정신역동적 접근 을 하기란 어렵다는 것을 깨달았다. 개인적인 갈등과 두려움 을 천천히 극복해 가면서 내 자신의 삶의 가치관과 직업적 정체성이 점차 상충되지 않고 통합되어 가는 경험을 하게 되었다.

실제 임상에서 신환을 만날 때 치료적 전략을 계획하는 데 에 약물치료밖에는 의존할 데가 없다고 느끼던 이전과는 달 리, 치료방법의 한계를 덜 느끼고 두려움이 줄어들었다. 초진 을 통해 얻을 수 있는 이해의 폭을 넓히게 되면서, 보다 더 효 과적인 치료법을 찾고, 환자가 자신의 문제에 대해 이해하고 적극적으로 치료에 참여할 수 있는 가능성이 높아졌다. 환자 의 가족들과 외부현실에까지 이해를 확장하면서 환자뿐 아 니라 환자를 도울 수 있는 주변 사람들의 자원까지도 활용할 수 있는 힘이 커지는 것을 느꼈다.

치료에 실패하거나, 환자가 치료에 저항하고 순응하지 않 을 경우 등, 다양한 장애에 대한 이해와 대처능력도 커졌으 며, 스스로에 대한 불신을 극복하면서 나의 역전이 감정을 솔 
직하고 보다 빨리 깨닫고 극복할 수 있게 되었다. 그 결과 환 자가 조기 탈락하지 않고 만족스러운 치료효과를 보게 되는 경우가 늘어났다.

\section{역동적 접근에 대한 환자들의 반응은 어떠한가?}

사람의 마음을 역동적 접근으로 이해한다는 것은, 표면적 으로 관찰할 수 없는, 때로는 겉으로 보이는 것과 정반대인 것 같은 사람 마음의 심층을 읽고 이해하고 확신을 가지게 돕 는 것이다. 대부분의 사람들의 일상적인 삶에서는 이러한 경 험을 하기는 힘들다고 생각한다. 심지어는 역동적 치료 상황 에서조차도 치료자가 자신의 역전이 문제 때문에 환자의 심 층의 마음을 이해하는 데 실패하는 일이 드물지 않다. 그러 므로 환자가 자신의 마음을 역동적으로 잘 이해하는 치료자 를 만난다는 것은 행운이다. 어쩌면 일생에 한 번 만날까 말까 한 경험이라고까지 감히 말하고 싶다. 그 환자는 자신이 불행 하다고 믿었던 삶을 매우 다른 시각에서 이해할 수 있게 되 고, 잠재된 행복을 누릴 수 있는 기회를 얻는 것이다.

하지만 모든 환자가 역동적인 이해를 필요로 하고, 활용할 수 있는 것은 아니다. 자신의 갈등을 피하지 않고 이해하는 것 이 어떤 사람의 경우에는 너무나 소중한 것을 포기해야 함을 의미할 때가 있다. 예를 들어 결혼 생활 동안 남편과 시댁, 자 녀들을 위해 고된 생활을 하면서 좌절과 분노를 억누르고 대 신 신체 증상에 몰두하며 자신을 괴롭히고 있는 주부의 경우 에, 자신의 분노를 깨닫고 피학적인 가족과의 관계를 통해 자 신이 가족들에게 중요하고 필요한 존재임을 확인하고, 신체 증상을 통해 가족들에게 의존하고 돌봄을 요구하는 기저의 소망이 있음을 이해하게 된 $\mathrm{A}$ 라는 환자와 $\mathrm{B}$ 라는 환자가 있 다고 가정하자( $\mathrm{A}$ 와 $\mathrm{B}$ 는 저자가 상상한 허구의 환자이다).

$\mathrm{A}$ 는 자신의 증상의 의미를 이해하게 되면서 자신이 얼마 나 가족들의 관심과 이해를 필요로 했었는지 스스로를 이해 하고 수용할 수 있게 되어서, 그런 자신을 스스로가 더 잘 돌 보고 싶어지고 이해하고 싶어졌다. $\mathrm{A}$ 는 자신에게 부당한 가 족들의 요구들을 조금씩 거절하고 자신을 위해 시간과 노력 을 사용하기 시작했다. 변한 $\mathrm{A}$ 의 태도에 가족들은 불편해 하 기 시작했고, 결혼한 장남은 $\mathrm{A}$ 가 경제적 지원을 줄이자 원망 하고 발길을 끊기도 했다. 하지만 $\mathrm{A}$ 의 신체 증상은 오히려 점차 호전되었고, 가족들도 $\mathrm{A}$ 에 대해 덜 걱정하고 조금씩 $\mathrm{A}$ 의 영역을 존중하기 시작했다.

이에 비해 $\mathrm{B}$ 는 자기 증상이 가족들의 보살핌을 원하고 있 다는 것을 이해했지만, 인정하기가 너무나 힘들었다. 언제나 자신이 가족들을 보살폈지, 한 번도 자신이 가족들에게 뭔가 요구했던 적이 없었는데, 자기 증상에 그런 소망이 있다는 것은 이기적이고 이중적인 행동이라고 느껴졌기 때문이다.
다른 가족들도 자기 증상이 그런 소망 때문이라고 생각한다 면 가족들로부터 비난받고 버림받게 될 것 같아서 두려움을 느꼈다. 만약에 가족 중의 누구라도 자신에게 등을 돌린다면 $\mathrm{B}$ 는 앞으로 살아갈 자신이 도저히 없었다. $\mathrm{B}$ 는 5 남매 중에 가운데 딸로 태어나 투명인간처럼 살면서 단 한 번도 가족 들에게 자신의 존재가 가치 있을 것이라고 느껴보지 못했다. 집안일과 일찍이 공장에서 돈을 벌어 가족들을 부양했다. $\mathrm{B}$ 는 자기가 그렇게 하지 않았다면 부모님과 형제들에게 자신 은 필요 없는 존재였을 것이고 부모님은 차라리 내가 태어 나지 않았기를 바라셨을 것 같다고 느꼈다. B에게 가족들의 관심은 곧 자신의 생명과 직결되는 느낌이었던 것이다. $\mathrm{B}$ 는 치료자가 해석하는 신체 증상의 심층의 의미가 치료자가 자 신을 비난하는 것으로 들려서 혼란스러웠고, 신체 증상은 일 시적으로 더 심해지고 치료자에게 고통을 하소연함으로써 치료자를 비난했다. 치료자가 B의 고통과 비난을 이해하고 수용하는 일관된 태도를 보이자 조금씩 적대적인 경계를 누 그러뜨렸지만, 신체 증상은 약물치료에 약간만 호전될 뿐이 었다.

위의 예는 역동정신의(psychodynamic psychiatrist) ${ }^{\mathrm{a}}$ 가 환 자를 이해한다는 것의 깊이를 보여주는 것이기도 하다. 환자 를 이해하는 것이 객관적이고 현상적인 사실의 그 이면을 읽어 낸다는 것이 아니라, 치료자 자신이 환자의 역동에 동참 해서 치료자가 그 환자의 정신적 현실(psychic reality)에서 어떤 위치에 있는지 이해하고 치료자와 환자의 상호작용을 이해하는 것이다. 역동정신의가 환자에게 보여주는 해석과 태도가 때로 환자에게는 과거의 아픔을 재현하게 하고, 상실 을 의미하며, 포기를 요구하는 것이 되기도 한다.

나의 임상경험에서는 역동적 이해를 경험한 환자들은 많 은 경우 긍정적인 반응을 보였다. 역동적인 이해를 경험한 환자는 이전의 대인관계에서보다 더 깊은 공감과 존중을 받 는 경험을 했다고 표현하고, 치료자와 좋은 동맹관계를 형성 했다. 치료자의 합리적인 초자아(reasonable superego)를 환 자가 내면화하면서 자아 기능이 회복되고, 대체로 실제 증상 이 호전되었다. 비교적 안정적인 성격 구조를 가진 신경증적 환자의 경우에는 단 한 가지의 역동적 이해라고 해도(예를 들어 자신의 신경증적 증상의 역동적 의미의 이해) 환자에 게 큰 영향을 주기도 했다.

하지만 환자의 성격구조를 충분히 이해하기 전에 너무 이 른 해석을 했을 경우 환자들은 오히려 이해받지 못했다고 느 ${ }^{a}$ 역동정신의(dynamic psychiatrist): 역동정신의학의 이론과 임상 실제에 전문적인 정신과 의사를 의미하며 정신분석과 정신분석적 정신치료를 통해 환자를 치료하고, 역동적 이해를 접목시켜서 다양 한 정신병리와 인간과 사회 현상에 대한 통찰을 통해 의학적 도움 을 주는 역할을 한다. 
끼고 심지어 비난을 당한다고 느껴 치료에 저항하는 경우도 있었다. 증상의 이면보다는 증상 자체에 충분히 관심을 가져 주기를 바라고, 지속적으로 신체화하는 경향을 보이는 경우 도 있고, 시간과 비용을 많이 투자해야 하는 역동적 치료 접 근에 불만과 부당함을 느끼는 경우도 있었다.

\section{정신과 임상에서 정신역동적 접근의 한계}

정신역동적 접근은 인간을 이해하는 수많은 방법 중 한 가 지 방법이다. 이 방법이 다른 접근법보다 더 우위에 있다고 할 수 없고, 모든 환자들에게 정신역동적 접근이 가장 좋은 치료법이라고도 할 수 없다. 또한 사람과 사회, 세계의 현상 에서 정신 역동의 틀에 맞춰 이해할 수 없는 것들이 많다는 것과 또 정신역동의학에 대해서도 우리가 모르는 것이 무한 하다는 것도 반드시 역동정신의들이 인정해야 하는 대목이 다. 역동정신의가 자신의 지식과 이해를 임상에서 활용하기 위해서는 환자의 동의와 협조가 반드시 필요하며, 환자는 그 것을 거부하고 저항할 권리도 가지고 있다. 그리고 신속하고 깊지 않은 치료를 원하는 환자의 필요도 존중해야 한다.

\section{결 론}

정신역동적 이해와 치료는 환자의 정신병리를 이해하고 치료하는 데 매우 유용하고 도움을 준다. 정신역동적 이해와 접근이 없이 환자의 성격구조가 정신병리에 어떤 영향을 주 고 치료과정이 어떻게 진행되는지를 파악하기란 불가능하 다고 할 수 있다. 그러나 현재 정신과 전공의의 수련과정에서
역동정신의학의 교육과 훈련이 부족하고, 전공의들 또한 역 동정신의학에 대한 더 충실한 수련을 원하고 있다는 것은 한국뿐 아니라 전 세계적인 현상이다.

정신역동적 이해와 치료는 많은 정신과 환자들의 임상치 료에서 치료의 효율을 높이고 좋은 결과를 보여주고 있다. 역동정신의가 보다 더 많이, 다양한 영역에서 활동하여 정신 의학과 환자의 임상치료, 더 나아가 사회의 병리적 현상에 대 한 대처에 이르기까지 도움이 될 수 있도록 해야 하며, 이것이 역동정신의들에게 부여된 의무이다.

\section{Acknowledgments}

본 원고 일부는 2015년 8월 29일 한국정신분석학회 하계워크숍 에서 구연하였음.

\section{Conflicts of Interest}

The author has no financial conflicts of interest.

\section{REFERENCES}

American Psychoanalytic Association. Standard for education and training in psychoanalysis [Internet]. New York: American Psychoanalytic Association;2015 [cited 2015 January 14]. Available from: http://www.apsa.org/sites/default/files/Standards\%20for\%20Education $\% 20$ and $\% 20$ Training.pdf.

Bahn GH. Anxiety and fear development: from the psychoanalysis to the neurobiological approach. Psychoanalysis 2014;25:54-64.

Gabbard GO. Psychodynamic psychiatry in clinical practice. 4th ed. New York: American Psychoanalytic publishing;2005. p.21-23.

Michels R. The future of psychoanalysis. Psychoanal Q 1988;57:167185.

Yu J, Ha JH. Expected promising future of psychoanalysis in Korea. Psychoanalysis 2015;26:75-81. 